\title{
High-Frequency Oscillatory Ventilation Versus Synchronized Intermittent Mandatory Ventilation Plus Pressure Support in Preterm Infants With Severe Respiratory Distress Syndrome
}

\author{
Huiqing Sun MD PhD, Rui Cheng MD PhD, Wengqing Kang MD, Hong Xiong MD, \\ Chongchen Zhou MD, Yinghui Zhang MD, Xiaoyang Wang MD PhD, and Changlian Zhu MD PhD
}

\begin{abstract}
BACKGROUND: Mechanical ventilation and surfactants are the standard treatment of preterm respiratory distress syndrome (RDS). The effects of the primary ventilation model on bronchopulmonary dysplasia (BPD) and long-term neurodevelopment outcomes are controversial. The purpose of this study was to compare the efficacy and safety of high-frequency oscillatory ventilation (HFOV) and synchronized intermittent mandatory ventilation plus pressure support ventilation (SIMV-PSV) in preterm infants with severe RDS. METHODS: A total of 366 eligible preterm infants were randomly assigned to treatment with HFOV $(n=184)$ or SIMV-PSV $(n=182)$. Surfactant was applied if $\mathrm{P}_{\mathrm{aO}} / \mathrm{F}_{\mathrm{IO}_{2}}$ was $<200 \mathrm{~mm} \mathrm{Hg}$ after 2 hours of ventilation. Primary outcomes were mortality or incidence of BPD. Secondary outcomes were duration of ventilation and hospitalization, surfactant requirements, pneumothorax, retinopathy of prematurity $\geq$ stage 2 , and neurodevelopment at 18 months of corrected age. RESULTS: Survival and complete outcome data were available for 288 infants at 18 months of corrected age. The incidence of death or BPD was significantly higher in the SIMV-PSV group $(P=.001)$. The duration of mechanical ventilation and hospitalization was shorter and the incidence of surfactant requirement and retinopathy of prematurity was lower in the HFOV group $(P<.001, P=.002, P=.04$, respectively). Moderate or severe neurological disability was less frequent in the HFOV group than in the SIMV-PSV group at 18 months $(P=.03)$. The combination of HFOV and surfactant dramatically reduced negative outcomes in preterm infants with severe RDS. CONCLUSIONS: Initial ventilation with HFOV in preterm infants with severe RDS reduces the incidence of death and BPD, and improves long-term neurodevelopment outcomes. (ClinicalTrials.gov NCT01496508) Key words: high-frequency oscillatory ventilation, respiratory distress syndrome, preterm infants, neurodevelopment. [Respir Care 2014;59(2):159-169. (C) 2014 Daedalus Enterprises]
\end{abstract}

\section{Introduction}

With the progress of medical technology and the development of neonatal ICUs (NICUs) in China, the survival

\footnotetext{
Drs Sun, Wang, and Zhu are affiliated with the Department of Pediatrics, Third Affiliated Hospital of Zhengzhou University, Zhengzhou, China. Drs Sun, Kang, Xiong, Zhou, and Zhang are affiliated with the Department of Pediatrics, Zhengzhou Children's Hospital, Zhengzhou, China. Dr Cheng is affiliated with the Department of Pediatrics, Children's Hospital of Nanjing Medical University, Nanjing, China. Dr Wang is also affiliated with the Henan Key Laboratory for Neonatal Brain Injury, Zhengzhou, China, and with the Perinatal Center, Sahlgrenska Academy, University of Gothenburg, Gothenburg, Sweden. Dr Zhu is also affiliated with the Center for Brain Repair and Rehabilitation, Institute of Neuroscience and Physiology, University of Gothenburg, Sweden.
}

of preterm infants has greatly improved. ${ }^{1}$ Respiratory distress syndrome (RDS) is common in preterm infants born

\footnotetext{
This study was partly supported by the Science and Technology Bureau of Zhengzhou, and the Department of Health and Department of Science and Technology of Henan Province, China. The authors have disclosed no conflicts of interest.

Correspondence: Huiqing Sun MD, Department of Neonatology, Zhengzhou Children's Hospital, Zhengzhou 450053, Zhengzhou, China. Email: s_huiqing@sina.com. Or Changlian Zhu MD PhD, Department of Pediatrics, Third Affiliated Hospital of Zhengzhou University, Zhengzhou 450052, China. E-mail: zhuc@zzu.edu.cn.
}

DOI: $10.4187 /$ respcare. 02382 
at $<32$ weeks of gestational age, ${ }^{2-4}$ and surfactant and mechanical ventilation have been the standard treatment. ${ }^{5}$ However, despite advances in neonatal respiratory care, a considerable number of preterm infants develop chronic lung disease, termed bronchopulmonary dysplasia (BPD), 5-8 that is associated with neonatal death, prolonged NICU stay, and impaired neurodevelopment. ${ }^{9}$ BPD has a multifactorial pathogenesis, and invasive mechanical ventilation is one of its most important causes.

\section{See the Related Editorial on Page 297}

High-frequency oscillatory ventilation (HFOV) was developed as a new ventilation technique in the late 1970s. Animal studies showed that HFOV produced less lung injury and improved pulmonary outcomes, compared to conventional mechanical ventilation. ${ }^{10}$ HFOV was expected to result in less BPD and mortality when used as a primary model of ventilation, compared to conventional mechanical ventilation in the treatment of RDS. ${ }^{8}$ However, there is disagreement regarding the advantage of HFOV over conventional mechanical ventilation in the treatment of RDS in preterm infants, with respect to the prevention of death, BPD, intraventricular hemorrhage (IVH), and periventricular leukomalacia over the short term. ${ }^{6,8,11-13}$ Even though a recent meta-analysis of individual patient data indicated that HFOV was as effective as conventional mechanical ventilation in preterm infants, ${ }^{6}$ the limited reports on the long-term effects of HFOV and conventional mechanical ventilation on the neurodevelopment of preterm infants with RDS are in disagreement. ${ }^{11,12}$ These conflicting results are probably due to heterogeneity in study design, patient characteristics, and outcome definition. Thus the safety and long-term neurodevelopmental outcomes of HFOV for preterm infants with severe RDS remain uncertain. Our hypothesis was that early use of HFOV with a lung volume recruitment strategy can provide a clinically important benefit in terms of mortality, incidence of BPD, and moderate to severe neurological disability at 18 months for infants with severe RDS born before 32 weeks, compared to conventional mechanical ventilation methods using synchronized intermittent mandatory ventilation plus pressure support ventilation (SIMV-PSV).

\section{Methods}

This prospective study was performed from June 2007 to December 2009 in Zhengzhou Children's Hospital of Henan Province and Nanjing Children's Hospital of Jiangsu Province, China. The ventilation strategies were performed identically at both study sites. This study was approved by

\section{QUICK LOOK}

\section{Current knowledge}

Surfactant replacement and positive-pressure support are the mainstays of treatment of respiratory distress in premature infants. Studies of the impact of the type of ventilatory support used on the development of chronic lung disease and neurological sequelae have had conflicting results.

\section{What this paper contributes to our knowledge}

Compared to pressure-limited synchronized intermittent mandatory ventilation with pressure support, highfrequency oscillation was associated with lower mortality, lower incidence of chronic lung disease, and better neurodevelopmental outcomes at 18 months.

the Life Science Ethics Committee of Zhengzhou University and the local research ethics committees at the participating centers, and in accordance with the Helsinki Declaration. Written informed consent was obtained from both parents when an infant was admitted to the NICU.

\section{Patient Population}

Patients eligible for the study were preterm infants admitted to the NICU with gestational age $<32$ weeks, birth weight $<1,500 \mathrm{~g}$, who developed RDS requiring mechanical ventilation $<24$ hours after birth, $\mathrm{P}_{\mathrm{aO}_{2}}$ ' $\mathrm{F}_{\mathrm{IO}_{2}}<200 \mathrm{~mm} \mathrm{Hg}$ (determined while on PEEP with nasal CPAP or conventional mechanical ventilation), and had radiographic evidence of severe RDS. In both NICUs at our institution, subjects with spontaneous breathing and respiratory distress were put on nasal CPAP. Subjects with worsening respiratory distress, hypoxemia, or recurrent apnea and bradycardia episodes were intubated and received mechanical ventilation via T-piece (Neopuff, Fisher \& Paykel Healthcare, Auckland, New Zealand). Infants in such cases had not been breathing spontaneously or nasal CPAP had failed. $\mathrm{P}_{\mathrm{aO}_{2}} / \mathrm{F}_{\mathrm{IO}_{2}}$ was determined at the time of randomization and throughout the study, when the infants were either on nasal CPAP with a pressure of $6 \mathrm{~cm} \mathrm{H}_{2} \mathrm{O}$ and $\mathrm{F}_{\mathrm{IO}_{2}}$ of $>0.5$ or were intubated with SIMV with peak inspiratory pressure (PIP) set at $20 \mathrm{~cm} \mathrm{H}_{2} \mathrm{O}$, PEEP of $5 \mathrm{~cm} \mathrm{H}_{2} \mathrm{O}$, and $\mathrm{F}_{\mathrm{IO}_{2}}$ of 0.4. Infants with genetic metabolic diseases, congenital abnormalities, pneumothorax, or grade III or IV intracranial hemorrhage before randomization were excluded, as were infants for whom parental consent could not be obtained. Switching from SIMV to HFOV, or vice-versa, was not allowed in instances of treatment failure (ie, crossover was not an option). HFOV- 


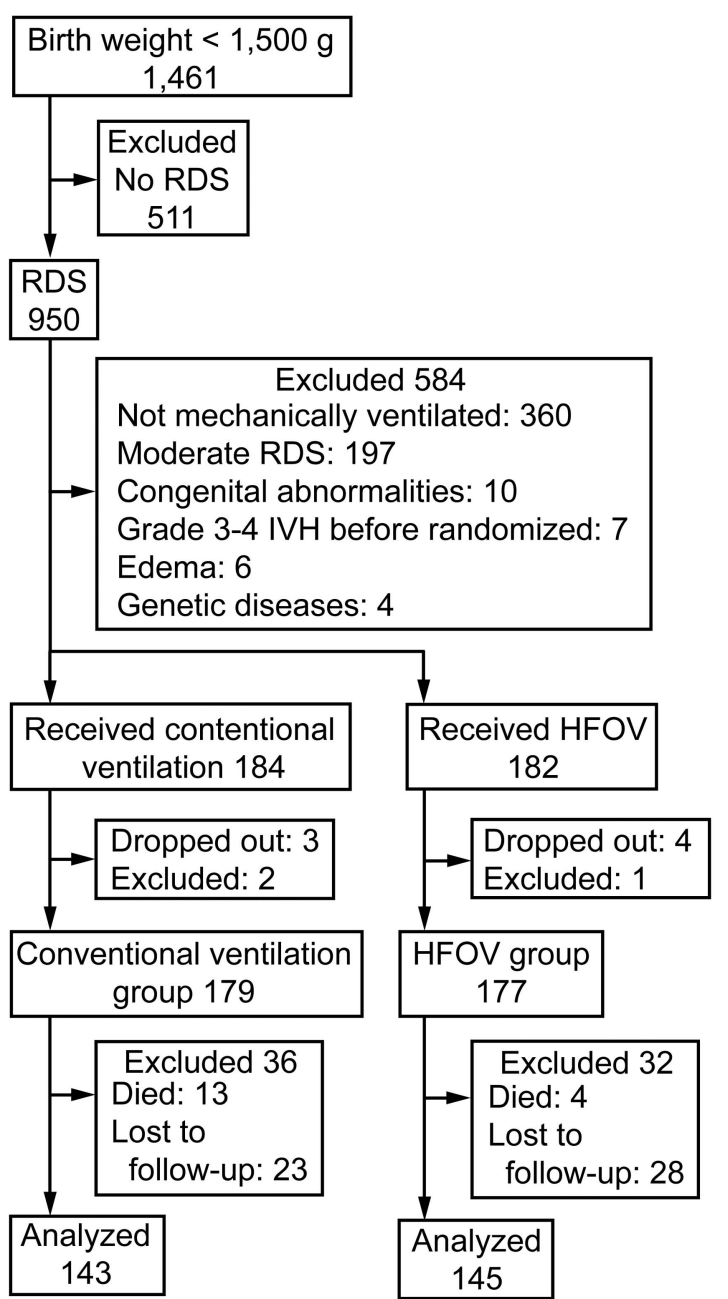

Fig. 1. Flow chart. The term "dropped out" refers to subjects whose parents requested withdrawal from the study. The term "lost to follow-up" means that contact with the family was lost during the follow-up period.

treated neonates who were reintubated were allowed to receive SIMV (for example, reintubation for apneas without evidence of pulmonary disease or established severe BPD). Those neonates were considered part of the HFOV group during statistical analysis.

A total of 1,461 preterm infants weighing $<1,500 \mathrm{~g}$ were admitted to the NICU during the study period, of which 950 had RDS and 366 met the criteria for entry into the study. One hundred eighty-four preterm infants were randomly assigned to receive SIMV-PSV, and 182 to receive HFOV, within $24 \mathrm{~h}$ of NICU admission, according to randomization by number. Two infants in the SIMVPSV group and one infant in the HFOV group with latediagnosed congenital heart disease were subsequently excluded. Seven infants dropped out during treatment, by parental request (Fig. 1).

\section{Randomization}

Subjects were assigned to the SIMV-PSV group or the HFOV group based on a computer-generated randomization plan. Randomization was stratified per center, according to sex and gestational age ( $<28$ weeks or $\geq 28$ weeks). The allocation ratio was $1: 1$, using variable block sizes. Randomization to the SIMV-PSV or HFOV group was carried out by random number allocation sequence, upon securing the order of admission to the NICU, and within 30 min after written informed consent was obtained.

\section{Ventilation Strategies}

We used a high-frequency infant ventilator (SLE5000, SLE, South Croydon, United Kingdom) and a conventional mechanical ventilator (Servo-i, Maquet, Wayne, New Jersey). The ventilation strategies for both groups aimed to emphasize lung recruitment and to avoid atelectasis. The optimal lung inflation was determined as expansion to 8-9.5 ribs for most of the infants, and 7-8 ribs for infants with air leak (emphysema or pneumothorax without drainage). ${ }^{14}$ Oxygenation was used as an indirect marker of ideal lung volume. Following intubation (the range of inner diameter of the endotracheal tubes was $2.5-3.0 \mathrm{~mm}$, and cuffed endotracheal tubes were not used), HFOV was initiated at a continuous distending pressure (CDP) of $6-8 \mathrm{~cm} \mathrm{H}_{2} \mathrm{O}$. CDP was increased in steps of $1-2 \mathrm{~cm} \mathrm{H}_{2} \mathrm{O}$, until oxygenation no longer improved or $\mathrm{F}_{\mathrm{IO}_{2}}$ was $\leq 0.25$ (opening pressure, opening CDP). Next the CDP was decreased in steps of 1-2 $\mathrm{cm} \mathrm{H}_{2} \mathrm{O}$, until oxygenation deteriorated, indicating alveolar collapse (closing CDP). The lung was then once again opened (opening CDP) and the pressure was set at $2 \mathrm{~cm} \mathrm{H}_{2} \mathrm{O}$ above the closing CDP (we called this the optimal CDP).

The time interval between pressure steps depended on the change in oxygenation. If oxygenation did not change following a pressure step, or if it stabilized after $\mathrm{F}_{\mathrm{IO}_{2}}$ adjustment, the clinician waited at least 2 min before taking the next pressure step. The pressure amplitude was set in such a way that chest oscillations were visible with a frequency of $10 \mathrm{~Hz}$. The inspiration time was set at the default values with the high-frequency ventilator. The pressure, amplitude, and frequency were kept constant during the recruitment procedure. ${ }^{15}$ If an infant received surfactant, the closing CDP, opening CDP, and optimal CDP were once more determined by the procedure described above, but with a minimum time interval of 5 min between the pressure steps. The procedure started with decremental pressure steps, unless the $\mathrm{F}_{\mathrm{IO}_{2}}$ increased to $>0.25$ after surfactant treatment, in which case CDP was increased in search of the new opening CDP. If the CDP could be reduced to $8 \mathrm{~cm} \mathrm{H}_{2} \mathrm{O}$ without compromising oxygenation, 
the closing procedure was stopped and the corresponding CDP was designated as the optimal CDP. ${ }^{15}$

During lung volume recruitment for HFOV, the expired tidal volume $\left(\mathrm{V}_{\mathrm{T}}\right)$, gas transport coefficient $\left(\mathrm{D}_{\mathrm{CO}_{2}}\right)$, pressure amplitude $(\Delta \mathrm{P})$, and mean airway pressure were measured dynamically with the high-frequency ventilator. $\mathrm{D}_{\mathrm{CO}_{2}}$ is analogous to minute ventilation during conventional mechanical ventilation. Minute ventilation is calculated as $\mathrm{V}_{\mathrm{T}} \times$ frequency, but in HFOV the value for $\mathrm{D}_{\mathrm{CO}_{2}}$ is calculated as $\mathrm{V}_{\mathrm{T}}{ }^{2} \times$ frequency. The compliance of the lung and the efficacy of lung volume recruitment were evaluated from the change in $\mathrm{V}_{\mathrm{T}}(2-2.5 \mathrm{~mL} / \mathrm{kg}$ will give normal $\mathrm{P}_{\mathrm{CO}_{2}}$ ), $\mathrm{D}_{\mathrm{CO}_{2}}$ (values around $80 / \mathrm{kg}$ will result in normocarbia), and oxygenation. This open lung approach is feasible in the majority of preterm infants with RDS, and does not lead to hemodynamic instability. Extubation was considered when $\mathrm{CDP}$ was $\leq 7 \mathrm{~cm} \mathrm{H}_{2} \mathrm{O}$ and the pressure amplitude of oscillation reached $10-15 \mathrm{~cm} \mathrm{H}_{2} \mathrm{O}$.

The SIMV-PSV was time-cycled, pressure-supported, pressure-limited, flow-triggered, and started exhaled $\mathrm{V}_{\mathrm{T}}$ of $4-6 \mathrm{~mL} / \mathrm{kg}$ (the preferred target range was $5-6 \mathrm{~mL} / \mathrm{kg}$ ), with PIP set to achieve adequate chest expansion (typically $14-20 \mathrm{~cm} \mathrm{H}_{2} \mathrm{O}$ ), and PEEP of 4-6 $\mathrm{cm} \mathrm{H}_{2} \mathrm{O}$. Our aim was to maintain lower $\mathrm{V}_{\mathrm{T}}(<6 \mathrm{~mL} / \mathrm{kg})$ by using lower PIP and optimal PEEP to maximize lung volume recruitment. Inspiratory time was $0.25-0.40 \mathrm{~s}$, breathing frequency was $\leq 60$ breaths/min (typically $30-40$ breaths/min plus pressure support), the level of pressure support was started at $50 \%$ of the PIP and thereafter maintained at or decreased gradually below that level to a minimum of $30 \%$ as tolerated, and $\mathrm{F}_{\mathrm{IO}_{2}}$ was set as required to maintain the target oxygenation. The flow trigger sensitivity was set at the maximum level. The weaning process was initiated when the following parameters were achieved: $\mathrm{PIP}<14 \mathrm{~cm} \mathrm{H}_{2} \mathrm{O}$, PEEP $<4 \mathrm{~cm} \mathrm{H}_{2} \mathrm{O}$, and $\mathrm{F}_{\mathrm{IO}_{2}}<0.3$. Extubation was considered when the subject's condition was stable for 12$24 \mathrm{~h}$ and adequate oxygenation could be maintained with an $\mathrm{F}_{\mathrm{IO}_{2}}<0.3$ and a breathing frequency $<25$ breaths/min.

All subjects were extubated from HFOV or SIMV-PSV to nasal CPAP (Infant Flow, CareFusion, San Diego, California), weaned to a nasal cannula, and then finally allowed to breathe room air. For both groups, successful extubation was defined as lasting $>72 \mathrm{~h}$ without clinical deterioration requiring reintubation. No subjects needed to be ventilated again within the $72 \mathrm{~h}$ following extubation.

\section{Surfactant Treatment}

In both groups, if $\mathrm{P}_{\mathrm{aO}_{2}} / \mathrm{F}_{\mathrm{IO}}$, was $<200 \mathrm{~mm} \mathrm{Hg}$ after 2 hours of ventilation, the subject was given rescue surfactant therapy (Curosurf, Cornerstone Therapeutics, Cary, North Carolina, $200 \mathrm{mg} / \mathrm{kg})$. A subsequent dose $(100 \mathrm{mg} /$ $\mathrm{kg}$ ) was administered $12 \mathrm{~h}$ after the first dose if $\mathrm{P}_{\mathrm{aO}_{2}} / \mathrm{F}_{\mathrm{IO}_{2}}$ remained $<200 \mathrm{~mm} \mathrm{Hg} .{ }^{16}$ The surfactant was adminis- tered via the in-line catheter, and suctioning was performed $6 \mathrm{~h}$ after surfactant administration (except in subjects who required suctioning sooner) via in-line suction catheter (Neonatal Closed Tracheal Suction System, Pacific Hospital Supply, Miaoli, Taiwan). Ventilation continued during the administration of surfactant and suctioning. Treatment with surfactant required permission from the parents, because surfactant is expensive and paid for by the parents. If permission could not be obtained, the infants were given rescue treatment instead of surfactant.

\section{Medical Treatment}

All infants in whom patent ductus arteriosus subsequently developed were treated with oral ibuprofen (indomethacin and ibuprofen are not given intravenously in China), or with surgical ligation without prophylactic ibuprofen. We followed established protocols for the use of diuretics and bronchodilators for chronic lung disease, without the use of steroids. Bronchodilator therapy was allowed, but not required, for infants $>14$ days old who were ventilated with $\mathrm{F}_{\mathrm{IO}_{2}}>0.4$. Diuretics were used sparingly if there were clinical/radiographic features of pulmonary edema in an infant with evolving or established BPD. ${ }^{17}$

\section{Data Collection}

All vital signs, including blood pressure, heart rate, oxygen saturation, ventilator settings, and arterial blood gases, were monitored both before and during mechanical ventilation, and $\mathrm{P}_{\mathrm{aO}} / \mathrm{F}_{\mathrm{IO}_{2}}$ was calculated. The primary outcomes were mortality and incidence of BPD, ${ }^{18}$ as determined by an oxygen reduction test at 36 weeks of postmenstrual age, and further graded by severity, using criteria adapted from the National Institute of Child Health and Human Development. Mild BPD was defined as the need for supplemental oxygen for $\geq 28$ days. Moderate BPD was defined as the need for supplemental oxygen at postmenstrual age of 36 weeks without positive pressure support. Severe BPD was defined as the need for mechanical ventilation.

Secondary outcomes were days on mechanical ventilation, hospital stay, surfactant requirement, and the occurrence of retinopathy of prematurity stage 2 or higher, pulmonary hemorrhage, patent ductus arteriosus, necrotizing enterocolitis, or pneumothorax. Long-term outcomes were moderate or severe disabilities at 18 months of corrected age, including severe hearing loss, blindness, cerebral palsy, or a mental developmental index $<70$, as determined by the Bayley Scales of Infant Development, second edition. Follow-up was performed in the Department of Child Healthcare of the 2 hospitals. Doctors were blind as to group allocation during follow-up until 18 months of corrected age. 
Table 1. Baseline Characteristics

\begin{tabular}{|c|c|c|c|}
\hline & $\begin{array}{l}\text { SIMV-PSV } \\
(n=179)\end{array}$ & $\begin{array}{l}\text { HFOV } \\
(n=177)\end{array}$ & $P$ \\
\hline Male/female, no. & $116 / 63$ & $112 / 65$ & .83 \\
\hline Gestational age, mean \pm SD weeks & $29.5 \pm 2.3$ & $29.3 \pm 2.5$ & .43 \\
\hline Birth weight, mean $\pm \mathrm{SD} g$ & $1117 \pm 241$ & $1129 \pm 199$ & .61 \\
\hline Apgar score at $5 \mathrm{~min}$, mean $\pm \mathrm{SD}$ & $7.5 \pm 1.2$ & $7.7 \pm 1.1$ & .10 \\
\hline Time to intubation, mean $\pm \mathrm{SD} h$ & $5.3 \pm 4.8$ & $5.7 \pm 5.0$ & .44 \\
\hline Time to randomization, mean $\pm \mathrm{SD} h$ & $5.9 \pm 5.1$ & $5.8 \pm 4.9$ & .85 \\
\hline $\begin{array}{l}\text { Number of nasal CPAP determining } \mathrm{P}_{\mathrm{aO}_{2}} / \mathrm{F}_{\mathrm{IO}_{2}} \text {, } \\
\text { no. }(\%)\end{array}$ & $23(13)$ & $19(11)$ & .62 \\
\hline $\begin{array}{l}\text { Number of conventional ventilation determining } \\
\mathrm{P}_{\mathrm{aO}_{2}} / \mathrm{F}_{\mathrm{IO}_{2}}, \text { no. }(\%)\end{array}$ & $156(87)$ & $158(89)$ & .62 \\
\hline Weight $<1,000 \mathrm{~g}$, no. $(\%)$ & $50(28)$ & $53(30)$ & .73 \\
\hline Prenatal steroids, no. $(\%)$ & $131(73)$ & $136(77)$ & .46 \\
\hline Maternal chorioamnionitis, no. (\%) & $14(8)$ & $12(7)$ & .84 \\
\hline Maternal diabetes, no. $(\%)$ & $4(2)$ & $5(3)$ & .75 \\
\hline Maternal hypertension, no. (\%) & $50(28)$ & $53(30)$ & .73 \\
\hline Preeclampsia, no. $(\%)$ & $9(5)$ & $10(6)$ & .82 \\
\hline Premature rupture of membrane, no. (\%) & $55(31)$ & $51(29)$ & .73 \\
\hline Twins or triplets, no. (\%) & $48(27)$ & $50(28)$ & .81 \\
\hline Fetal distress, no. (\%) & $41(23)$ & $38(21)$ & .80 \\
\hline Intrauterine growth retardation, no. (\%) & $11(6)$ & $9(5)$ & .82 \\
\hline Sepsis, no. $(\%)$ & $36(20)$ & $34(19)$ & .89 \\
\hline
\end{tabular}

SIMV-PSV $=$ synchronized intermittent mandatory ventilation with pressure support ventilation $\mathrm{HFOV}=$ high-frequency oscillatory ventilation

\section{Statistical Analyses}

The minimum sample size of 172 in each group was estimated based on an expected negative outcome in the SIMV-PSV group of 25\%, a 2-sided .05 significance level, an $80 \%$ chance of detecting a relative $30 \%$ decrease in frequency, and an estimated $15 \%$ loss to follow-up. Analyses were performed according to the intention-to-treat principle, and all who could be evaluated were included.

All analyses were performed with statistics software (SPSS 17.0, SPSS Chicago, Illinois). Quantitative data are expressed as mean $\pm \mathrm{SD}$. Entry data and outcome differences were compared with the $t$ test and Fisher exact test. Comparison of mean airway pressure, $\mathrm{P}_{\mathrm{aO}_{2}} / \mathrm{F}_{\mathrm{IO}_{2}}$, and $\mathrm{P}_{\mathrm{aCO}_{2}}$ between continuous variables was by one-way analysis of variance with 2 -tailed $P$ values. Subgroup interaction analyses were performed on the basis of sex, gestational age, birth weight, single or multiple births, antenatal steroid or postnatal surfactant treatment, and intubation time for mechanical ventilation. All subgroup statistical analyses were evaluated with the Breslow-Day test for interaction. The kappa test was used to examine whether the results were consistent between the 2 centers. The level of statistical significance was set at $P<.05$.

\section{Results}

\section{Respiratory Parameters}

Respiratory analyses were performed on the 179 infants in the SIMV-PSV group and the 177 infants in the HFOV group. There were no differences in baseline characteristics between the groups (Table 1). Mean airway pressure, $\mathrm{P}_{\mathrm{aO}} / \mathrm{F}_{\mathrm{IO}_{2}}$, and $\mathrm{P}_{\mathrm{aCO}}$ were not significantly different between the SIMV-PSV and HFOV groups before randomization. The changes in these parameters during the first 48 hours are shown in Figure 2, and a significant difference was observed at $4 \mathrm{~h}$ after ventilation. The $\mathrm{P}_{\mathrm{aCO}}$ reduction occurred more quickly with HFOV than with SIMV-PSV.

\section{Outcomes}

Seventeen preterm infants died during treatment: 13 in the SIMV-PSV group $(13 / 179=7.3 \%)$ ( 5 from pulmonary hemorrhage, 3 from renal failure, 2 from stage III necrotizing enterocolitis, 2 from sepsis, and 1 who did not respond to SIMV-PSV and surfactant), and 4 in the HFOV group $(4 / 177=2.3 \%, P=.04)$ ( 2 from pulmonary hemorrhage, 1 from renal failure, and 1 from sepsis). A 

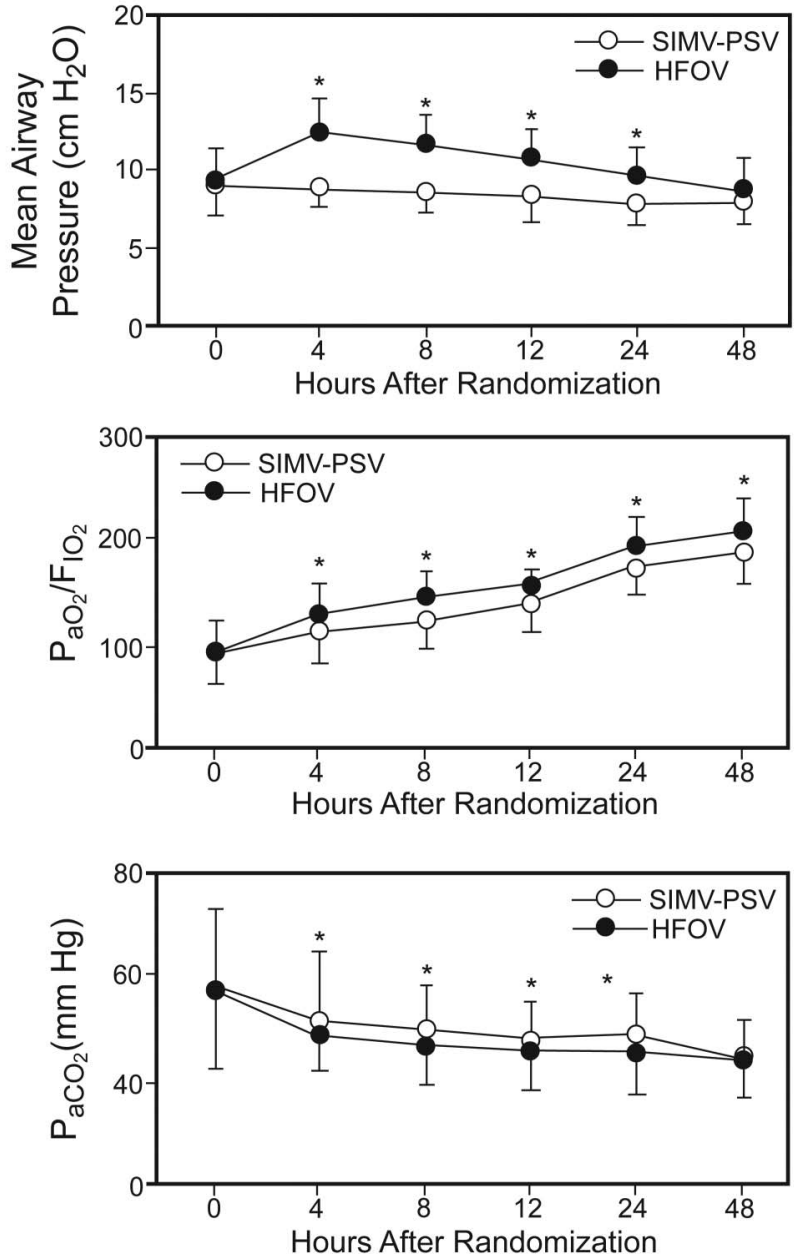

Fig. 2. Mean airway pressure, $\mathrm{P}_{\mathrm{aO}_{2}} / \mathrm{F}_{1 \mathrm{O}_{2}}$, and $\mathrm{P}_{\mathrm{aCO}}$, before and for the first $48 \mathrm{~h}$ after randomization. ${ }^{*} P<.05$. HFOV $=$ highfrequency oscillatory ventilation. SIMV-PSV = synchronized intermittent mandatory ventilation with pressure support ventilation.

total of 41 preterm infants were diagnosed with BPD at 36 weeks post-menstrual age: 28 in the SIMV-PSV group $(28 / 166=16.9 \%)$, and 13 in the HFOV group $(13 /$ $173=7.5 \%, P=.02$ ). A total of 58 preterm infants died or were diagnosed with BPD: 41 in the SIMV-PSV group $(41 / 179=22.9 \%)$, and 17 in the HFOV group $(13 / 177=9.6 \%)(P=.001)$ (Table 2$)$. In the Zhengzhou center the number of infants suffering from BPD in the SIMV-PSV group was 16/92, and in the HFOV group it was 6/93. The number of deaths in the SIMV-PSV group was $7 / 99$, and in the HFOV group it was $2 / 99$. In the Nanjing center the number of infants suffering from BPD in the SIMV-PSV group was $12 / 74$, and in the HFOV group it was 7/82. The number of deaths in the SIMV-PSV group was $6 / 80$, and in the HFOV group it was $2 / 84$. The results were consistent between the 2 centers $(P>.40$ via kappa test).
Subgroup analyses for primary outcomes were stratified according to sex, gestational age, birth weight, antenatal steroid or surfactant use, intubation time, and multiple births. There were no differences in basic characteristics between the SIMV-PSV and HFOV groups, except that the rate of surfactant use was lower in the HFOV group $(P=.001)$ (Table 3$)$. The significantly improved outcomes with HFOV were in the infants $<28$ weeks gestational age, via chi-square test $(P=.02)$. However, the subgroup statistical analyses evaluated with the BreslowDay test for interaction did not show significant differences for the effects of gestational age, sex, birth weight, antenatal steroid use, surfactant treatment, intubation time, or multiple births on BPD, or death between the SIMVPSV and HFOV groups (Table 4). The incidence of death or BPD in the SIMV-PSV group without surfactant treatment was 33\%, and the incidence of death or BPD in the SIMV-PSV with surfactant or HFOV without surfactant groups was about $15 \%$, and was similar in the 2 groups. The incidence of death or BPD in the HFOV with surfactant group was $4 \%$, and this was $88 \%$ less than in the SIMV-PSV without surfactant group (see Table 4).

The duration of mechanical ventilation and hospital stay in the survivors was shorter in the HFOV group than in the SIMV-PSV group $(P<.001$ and $P=.04$, respectively). Surfactant was required in $45 \%$ of the HFOV group, and in $62 \%$ of the SIMV-PSV group $(P=.002)$. Retinopathy of prematurity $\geq$ stage 2 was twice as frequent in the SIMV-PSV group as in the HFOV group $(P=.04)$. The rate of pulmonary hemorrhage was $15 \%$ in the SIMV-PSV group, and $8 \%$ in the HFOV group $(P=.045)$. There was no difference in the occurrence of patent ductus arteriosus, necrotizing enterocolitis, or pneumothorax between the 2 groups (Table 5).

Long-term neurodevelopmental outcomes at 18 months of corrected age were available for 143 subjects in the SIMV-PSV group and 145 subjects in the HFOV group $(288 / 356=81 \%)$. Seventeen subjects $(13$ in the SIMVPSV group and 4 in the HFOV group) died in the hospital, and 51 subjects ( 23 in the SIMV-PSV group and 28 in the HFOV group) were lost to follow-up (the clinical characteristics were no different between the 2 groups). The incidence of severe hearing loss and visual impairment was similar between the SIMV-PSV and the HFOV groups. Of the 288 infants, 19 developed cerebral palsy (6.6\%), including 14 in the SIMV-PSV group and 5 in the HFOV group $(P=.03)$. The incidence of mental developmental index $<70$ was significantly higher in the SIMV-PSV group, compared to the HFOV group $(P=.03)$ (Table 6).

\section{Discussion}

The debate on whether HFOV or conventional mechanical ventilation is the best ventilation strategy to support 
Table 2. Primary Outcomes

\begin{tabular}{lcccc}
\hline \hline & $\begin{array}{c}\text { SIMV-PSV } \\
\text { no. }(\%) \\
(n=179)\end{array}$ & $\begin{array}{c}\text { HFOV } \\
\text { no. }(\%) \\
(n=177)\end{array}$ & $\begin{array}{c}\text { Relative } \\
\text { Risk }\end{array}$ & $\begin{array}{c}95 \% \text { CI } \\
\text { Death or BPD }\end{array}$ \\
Death & $41 / 179(22.9)$ & $17 / 177(9.6)$ & 0.42 & $0.25-0.71$ \\
BPD at 36 weeks & $13 / 179(7.3)$ & $4 / 177(2.3)$ & 0.31 & $0.10-0.94$ \\
Severe BPD & $28 / 166(16.9)$ & $13 / 173(7.5)$ & 0.45 & $0.24-0.83$ \\
& $10 / 166(5.4)$ & $3 / 173(1.7)$ & 0.29 & .04 \\
\end{tabular}

SIMV-PSV $=$ synchronized intermittent mandatory ventilation with pressure support ventilation

$\mathrm{HFOV}=$ high-frequency oscillatory ventilation

$\mathrm{BPD}=$ bronchopulmonary dysplasia

Table 3. Subgroups According to Baseline Characteristics

\begin{tabular}{|c|c|c|c|c|c|}
\hline & $\begin{array}{c}\text { SIMV-PSV } \\
\text { no. }(\%)\end{array}$ & $\begin{array}{l}\text { HFOV } \\
\text { no. (\%) }\end{array}$ & $\begin{array}{c}\text { Total } \\
\text { no. }(\%)\end{array}$ & Chi-Square & $P$ \\
\hline \multicolumn{6}{|l|}{ Sex } \\
\hline Male & $116(65)$ & $112(63)$ & $228(64)$ & 0.09 & .76 \\
\hline Female & $63(35)$ & $65(37)$ & $128(36)$ & & \\
\hline \multicolumn{6}{|c|}{ Gestational age, weeks } \\
\hline$<28$ & $53(30)$ & $56(32)$ & $109(31)$ & 2.05 & .36 \\
\hline $28-30$ & $110(61)$ & $112(63)$ & $222(62)$ & & \\
\hline $30-32$ & $16(9)$ & $9(5)$ & $25(7)$ & & \\
\hline \multicolumn{6}{|l|}{ Birth weight, $g$} \\
\hline$<1,000$ & $50(28)$ & $53(30)$ & $103(29)$ & 0.18 & .68 \\
\hline $1,000-1,500$ & $129(72)$ & $124(70)$ & $253(71)$ & & \\
\hline \multicolumn{6}{|c|}{ Antenatal steroids } \\
\hline Yes & $131(73)$ & $136(77)$ & $267(75)$ & 0.63 & .43 \\
\hline No & 48 (27) & $41(23)$ & $89(25)$ & & \\
\hline \multicolumn{6}{|l|}{ Surfactant } \\
\hline Yes & $110(61)$ & $79(45)$ & $189(53)$ & 10.11 & .002 \\
\hline No & 69 (39) & $98(55)$ & $167(47)$ & & \\
\hline \multicolumn{6}{|c|}{ Time to intubation } \\
\hline$<4 \mathrm{~h}$ & $88(49)$ & $89(50)$ & $177(50)$ & 0.05 & .83 \\
\hline$>4 \mathrm{~h}$ & $91(51)$ & $88(50)$ & $179(50)$ & & \\
\hline \multicolumn{6}{|l|}{ Multiple births } \\
\hline Single & $131(73)$ & $127(72)$ & $258(72)$ & 0.09 & .76 \\
\hline Twins & $48(27)$ & $50(28)$ & $98(28)$ & & \\
\hline
\end{tabular}

SIMV-PSV = synchronized intermittent mandatory ventilation with pressure support ventilation HFOV = high-frequency oscillatory ventilation

premature infants with RDS has gone on for more than 20 years. ${ }^{6}$ A Cochrane review that evaluated 17 studies that included 3,652 infants failed to obtain conclusive evidence as to which type of mechanical ventilation is more effective, and no Chinese population study was included in that review. ${ }^{19}$ The conflicting reports about HFOV versus conventional mechanical ventilation are probably due to heterogeneity in study design, subject characteristics, and outcome definition. Furthermore, the long-term neurodevelopmental outcomes of employing different kinds of ventilation initially for preterm infants with severe RDS are still uncertain. ${ }^{11,12,20}$
Our prospective and randomized investigation of initial use of HFOV versus SIMV-PSV in preterm Chinese infants with severe RDS found that the infants receiving HFOV had a significantly reduced incidence of death or BPD, shorter mechanical ventilation and stay, and less neurological disability at 18 months of age. HFOV based on the optimal lung volume strategy improves survival without increasing the incidence of chronic lung disease. ${ }^{21}$ As demonstrated in animal models, HFOV improved lung function and mechanics and reduced inflammatory mediator levels. ${ }^{8}$ Animals receiving HFOV with an optimal lung volume strategy showed early and sustained improve- 
Table 4. Subgroup Analyses for Primary Outcomes

\begin{tabular}{|c|c|c|c|c|c|c|c|c|c|c|c|c|c|c|}
\hline & \multicolumn{5}{|c|}{ Death or BPD $(n=58)$} & \multicolumn{4}{|c|}{ Death $(n=17)$} & \multicolumn{5}{|c|}{$\operatorname{BPD}(n=41)$} \\
\hline & $\begin{array}{c}\text { SIMV-PSV } \\
\text { no. }(\%)\end{array}$ & $\begin{array}{l}\text { HFOV } \\
\text { no. }(\%)\end{array}$ & $\begin{array}{l}\text { Relative } \\
\text { Risk }\end{array}$ & $95 \% \mathrm{CI}$ & $P^{*}$ & $\begin{array}{l}\text { SIMV-PSV } \\
\text { no. }(\%)\end{array}$ & $\begin{array}{l}\text { HFOV I } \\
\text { no. (\%) }\end{array}$ & $\begin{array}{l}\text { Relative } \\
\text { Risk }\end{array}$ & $95 \% \mathrm{CI}$ & $\begin{array}{c}P^{*} \begin{array}{l}\text { SIMV-PSV } \\
\text { no. }(\%)\end{array}\end{array}$ & $\begin{array}{l}\text { HFOV } \\
\text { no. (\%) }\end{array}$ & $\begin{array}{l}\text { Relative } \\
\text { Risk }\end{array}$ & $95 \% \mathrm{CI}$ & $P^{*}$ \\
\hline Sex & & & & & .84 & & & & & .79 & & & & .71 \\
\hline Male & $28 / 116(24)$ & $11 / 112(10)$ & 0.41 & $0.21-0.78$ & & $9 / 116(8)$ & $3 / 112(3)$ & 0.35 & $0.10-1.24$ & 19/107 (18) & $8 / 109(7)$ & 0.41 & $0.19-0.90$ & \\
\hline Female & $13 / 63(21)$ & $6 / 65(9)$ & 0.45 & $0.18-1.10$ & & $4 / 63(6)$ & $1 / 65(2)$ & 0.24 & $0.03-2.11$ & 9/59 (15) & 5/64 (8) & 0.51 & $0.18-1.44$ & \\
\hline $\begin{array}{c}\text { Gestational age, } \\
\text { weeks }\end{array}$ & & & & & .72 & & & & & .06 & & & & .53 \\
\hline$<28$ & $21 / 53(40)$ & $10 / 56(18)$ & 0.45 & $0.24-0.87$ & & 9/53 (17) & 2/55 (4) & 0.21 & $0.05-0.95$ & $12 / 44(27)$ & $8 / 53(15)$ & 0.54 & $0.24-1.21$ & \\
\hline $28-30$ & $19 / 110(16)$ & $6 / 112(4)$ & 0.31 & $0.13-0.75$ & & $4 / 110(4)$ & $1 / 112(1)$ & 0.25 & $0.03-2.16$ & $15 / 106(14)$ & $5 / 111(5)$ & 0.26 & $0.12-0.85$ & \\
\hline $30-32$ & $2 / 16(13)$ & $1 / 9(11)$ & 0.89 & $0.09-8.50$ & & $0 / 16(0)$ & $1 / 9(1)$ & & & $1 / 16(6)$ & $0 / 8(0)$ & & & \\
\hline Birth weight, $g$ & & & & & .83 & & & & & .56 & & & & .47 \\
\hline$<1,000$ & $18 / 50(43)$ & 9/53 (17) & 0.47 & $0.23-0.95$ & & $8 / 50(16)$ & $2 / 53(4)$ & 0.24 & $0.05-1.06$ & $10 / 42(24)$ & $7 / 51(14)$ & 0.58 & $0.24-1.38$ & \\
\hline $1,000-1,500$ & $23 / 129(18)$ & $8 / 124(6)$ & 0.36 & $0.17-0.78$ & & $5 / 129(4)$ & $2 / 124(2)$ & 0.42 & $0.08-2.11$ & $18 / 122(15)$ & $6 / 122(5)$ & 0.33 & $0.14-0.81$ & \\
\hline Antenatal steroid & & & & & .47 & & & & & .15 & & & & .90 \\
\hline Yes & 23/131 (18) & $8 / 136(6)$ & 0.34 & $0.16-0.72$ & & $8 / 131(6)$ & $1 / 136(1)$ & 0.12 & $0.02-0.95$ & $15 / 123(12)$ & $7 / 135(5)$ & 0.43 & $0.18-1.01$ & \\
\hline No & $18 / 48(38)$ & 9/41 (22) & 0.59 & $0.30-1.16$ & & $5 / 48(10)$ & $3 / 41(7)$ & 0.70 & $0.18-2.76$ & $13 / 43(30)$ & $6 / 38(16)$ & 0.52 & $0.22-1.24$ & \\
\hline Surfactant & & & & & .50 & & & & & .86 & & & & .48 \\
\hline Yes & $18 / 110(16)$ & $3 / 79(4)$ & 0.23 & $0.07-0.76$ & & $6 / 110(5)$ & $1 / 79(1)$ & 0.23 & $0.03-1.89$ & $12 / 104(12)$ & 2/78 (3) & 0.22 & $0.05-0.96$ & \\
\hline No & $23 / 69(33)$ & $14 / 98(14)$ & 0.43 & $0.24-0.77$ & & $7 / 69(10)$ & 3/98 (3) & 0.30 & $0.08-1.13$ & $16 / 62(26)$ & $11 / 95(12)$ & 0.45 & $0.22-0.90$ & \\
\hline Time to intubation & & & & & .61 & & & & & .43 & & & & .91 \\
\hline$<4 \mathrm{~h}$ & $32 / 88(36)$ & $13 / 89(15)$ & 0.40 & $0.23-0.71$ & & 9/88 (10) & 2/89 (2) & 0.22 & $0.05-0.99$ & 23/79 (29) & $11 / 87(13)$ & 0.43 & $0.23-0.83$ & \\
\hline$>4 \mathrm{~h}$ & 9/91 (10) & $4 / 88(5)$ & 0.46 & $0.15-1.44$ & & 4/91 (4) & $2 / 88(2)$ & 0.52 & $0.10-2.75$ & $5 / 87(6)$ & $2 / 86(2)$ & 0.41 & $0.08-2.03$ & \\
\hline Multiple births & & & & & .48 & & & & & .36 & & & & .99 \\
\hline Single & 27/131 (21) & $9 / 127(8)$ & 0.34 & $0.17-0.70$ & & $7 / 131(5)$ & $1 / 127(1)$ & 0.15 & $0.02-1.18$ & $20 / 124(16)$ & $9 / 126(7)$ & 0.44 & $0.21-0.94$ & \\
\hline Twins & $14 / 48(29)$ & $8 / 50$ (18) & 0.55 & $0.25-1.19$ & & $6 / 48(13)$ & $3 / 50(6)$ & 0.48 & $0.13-1.81$ & $8 / 42(19)$ & $4 / 47(9)$ & 0.45 & $0.15-1.38$ & \\
\hline
\end{tabular}

Table 5. Secondary Outcomes

\begin{tabular}{|c|c|c|c|}
\hline & $\begin{array}{c}\text { SIMV-PSV } \\
\text { no. }(\%) \\
(n=179)\end{array}$ & $\begin{array}{c}\text { HFOV } \\
\text { no. }(\%) \\
(n=177)\end{array}$ & $P$ \\
\hline Mechanical ventilation, $\mathrm{d}$ & $5.7 \pm 5.0$ & $4.0 \pm 4.0$ & $<.001$ \\
\hline Hospital stay for survivors, $\mathrm{d}$ & $31.6 \pm 21.7$ & $27.0 \pm 20.2$ & .04 \\
\hline Intracranial hemorrhage grade III or IV & $27 / 179(15)$ & $30 / 177(17)$ & .67 \\
\hline Periventricular leukomalacia & $16 / 179(9)$ & $10 / 177(6)$ & .31 \\
\hline Surfactant requirement & $110 / 179(61)$ & $79 / 177(45)$ & .002 \\
\hline Surfactant requirement $>1$ dose & $40 / 179(22)$ & 18/177 (10) & .002 \\
\hline Timing of surfactant $>1$ dose & $13.9 \pm 2.7$ & $19.3 \pm 2.5$ & $<.001$ \\
\hline Retinopathy of prematurity $\geq$ stage 2 & $19 / 179(11)$ & 8/177 (5) & .04 \\
\hline Pulmonary hemorrhage & $27 / 179(15)$ & $14 / 177(8)$ & .045 \\
\hline Patent ductus arteriosus & $45 / 179(25)$ & $41 / 177(23)$ & .71 \\
\hline Necrotizing enterocolitis & $16 / 179(9)$ & $13 / 177(7)$ & .7 \\
\hline Pneumothorax & $21 / 179(12)$ & $10 / 177(6)$ & .06 \\
\hline
\end{tabular}

SIMV-PSV $=$ synchronized intermittent mandatory ventilation with pressure support ventilation

HFOV = high-frequency oscillatory ventilation

ment in pulmonary mechanics and gas exchange. ${ }^{22}$ Early and exclusive use of HFOV combined with an optimal lung volume strategy was beneficial during the acute phase of lung injury, ${ }^{23}$ and may be associated with better neuromotor outcomes. ${ }^{12}$
RDS occurs in about $50 \%$ of preterm infants born at $<30$ weeks of gestational age, and mechanical ventilation and surfactant therapy have become the standard of care in such cases. However, BPD and severe brain injury remain the major causes of morbidity in preterm infants. There is 
Table 6. Neurodevelopmental Outcomes at 18 Months of Corrected Age

\begin{tabular}{lccc}
\hline \hline & $\begin{array}{c}\text { SIMV-PSV } \\
\text { no. }(\%) \\
(n=143)\end{array}$ & $\begin{array}{c}\text { HFOV } \\
\text { no. }(\%)\end{array}$ & $P$ \\
\hline Cerebral palsy & $14 / 143(10)$ & $5 / 145(3)$ & .03 \\
Mental developmental index $<70$ & $45 / 143(31)$ & $29 / 145(20)$ & .03 \\
Visual impairment & $4 / 143(3)$ & $2 / 145(1)$ & .45 \\
Severe hearing loss & $4 / 143(3)$ & $3 / 145(2)$ & .72 \\
& & & \\
SIMV-PSV = synchronized intermittent mandatory ventilation with pressure support & \\
ventilation & & & \\
HFOV = high-frequency oscillatory ventilation & & & \\
& & & \\
\hline
\end{tabular}

growing evidence that the strategy used during mechanical ventilation may influence the pulmonary outcome in preterm infants with RDS. HFOV is believed to cause less injury to the immature lung than are other mechanical ventilation techniques, and several reports have found that HFOV improves pulmonary outcomes in preterm infants with RDS to a greater extent than conventional mechanical ventilation. ${ }^{8,13}$ Other studies, however, did not show a clear benefit on respiratory outcome from HFOV. ${ }^{11}$

The effects of HFOV on the brain are also controversial. Some studies suggest an increased risk of both IVH and periventricular leukomalacia, ${ }^{16}$ but other randomized controlled trials of HFOV reported no difference ${ }^{11,21}$ or reduced rates of cerebral palsy. ${ }^{12}$ IVH and periventricular leukomalacia are major risk factors for poor neurodevelopmental outcomes in extremely premature infants. ${ }^{24}$ In our study the incidence of cerebral palsy or mental developmental index $<70$ was higher in the SIMV-PSV group than in the HFOV group (see Table 6). This is not likely to be related to the relatively high gestational age in the SIMV-PSV group, because the mean gestational age between the 2 groups was not different (see Table 1). Furthermore, both IVH and periventricular leukomalacia are maturation-dependent events, with potential for the subsequent occurrence of cognitive, behavioral, or attention deficits, as well as cerebral palsy. ${ }^{25,26}$ The relatively high gestational age should result in relatively low incidences of cerebral palsy or mental developmental index $<70$. In our study we found no differences in the occurrence of IVH or periventricular leukomalacia between the groups, but the incidence of cerebral palsy was 3 times higher in the SIMV-PSV group. This indicates that either the predictive value of IVH or periventricular leukomalacia, or both, is limited, or that the neonatal brain has a substantial degree of plasticity.

Previous studies on long-term neurological outcomes among preterm infants report conflicting results. ${ }^{11,12,20}$ In our study we found a lower incidence of moderate or severe disability in the HFOV group, compared to the SIMV-PSV group, in contrast to previous reports, thus indicating that HFOV is relatively safe and effective in treating preterm infants with severe RDS. The discrepancy between our current results and those of previous studies is probably attributable to differences in study inclusion criteria or study populations.

Exogenous surfactant is the undisputed first-line treatment of choice for RDS in preterm infants in developed countries. However, the high cost of surfactant and basic neonatal supportive care is a barrier to surfactant therapy in low-income countries. ${ }^{27}$ Exogenous surfactant is expensive and is not used prophylactically for every preterm infant, especially in small towns and rural areas. A recent retrospective investigation of neonatal respiratory failure in China showed that about $50 \%$ of all infants with RDS were treated with surfactant, which was similar to what our study found. ${ }^{28}$ The introduction of surfactant significantly reduced mortality in infants with $\mathrm{RDS},{ }^{29}$ so prophylactic surfactant treatment in extremely preterm infants has been recommended, along with protocols on the timing of administration, the surfactant preparation, and the dosage regimen. ${ }^{30}$

Despite the effectiveness of surfactant treatment in cases of RDS, BPD remains an important adverse outcome in preterm infants, and its incidence has been directly related to the duration of invasive ventilation. ${ }^{31}$ For this reason, pressure support ventilation and volume guarantee are 2 new neonatal ventilation techniques that have been developed to avoid overdistention and atelectasis. ${ }^{32}$ This noninvasive ventilation strategy combines nasal CPAP with a method of selective surfactant administration, and has shown results similar to prophylactic surfactant treatment. ${ }^{33}$ However, an early prediction of nasal CPAP failure in preterm infants with early surfactant rescue treatment is important to reduce BPD. ${ }^{34}$ Nasal CPAP has redefined the care of premature neonates, but does not sufficiently offload the burden of high work of breathing, nor is nasal CPAP capable of providing effective alveolar ventilation for neonates whose condition worsens. As such, approximately $50-67 \%$ of very-low-birth-weight premature neonates supported initially with nasal CPAP develop severe respiratory failure that requires intubation and invasive ventilation. Approximately $25-38 \%$ of all premature infants, regardless of birth weight, fail nasal CPAP following surfactant administration and require reintubation. ${ }^{35}$

HFOV combined with an optimum volume strategy reduces the need for supplemental surfactant ${ }^{16,23}$ without negatively influencing outcomes. ${ }^{4}$ In our study the need for early surfactant rescue was significantly less in the HFOV group than in the SIMV-PSV group. Moreover, the incidence of BPD and mortality was lowest in the HFOVplus-surfactant rescue group. These results show that outcomes can be significantly improved if surfactant is used selectively during HFOV in preterm infants with RDS. 
Some limitations in our study must be mentioned. First, the number of subjects lost to follow-up was quite high. This was probably related to a lack of health insurance, the high cost of hospitalization, the fact that some parents were unable to afford the cost of medical treatment, or the poor prognoses of the most severe cases. The migration of some families from rural to urban areas might be another reason cases were lost to follow-up. Second, surfactant was not used in all subjects, due to its high cost. The decision of whether to administer surfactant was determined in consultation between doctors and parents, and was based on family income. This is an important problem, especially for patients from rural areas. Third, there were more male than female subjects, and a similar trend has been reported in other studies in Chinese populations. ${ }^{28,36}$ This imbalance in sex ratio is reportedly related to China's one-child policy, illegal prenatal screening, and sex-selective abortion in rural areas. ${ }^{37}$ The sex effect on the morbidity and mortality of premature infants has been reported previously. ${ }^{38}$ Finally, we included some infants born at 31-32 weeks of gestation, which is relatively mature, although nowadays they would be less likely to be ventilated. However, the number of such patients was very small and probably did not affect our results.

\section{Conclusions}

Despite those limitations, our study indicates that initial HFOV is safe and effective in reducing mortality, the incidence of BPD, and neurodevelopmental disabilities at 18 months of age in a Chinese population of preterm infants with severe RDS.

\section{ACKNOWLEDGMENTS}

We are grateful to the families who consented to participate in the study.

\section{REFERENCES}

1. Huo K, Zhao Y, Feng H, Yao M, Savman K, Wang X, et al. Mortality rates of children aged under five in Henan province, China, 2004-2008. Paediatr Perinat Epidemiol 2010;24(4):343-348.

2. Kaplan HC, Lorch SA, Pinto-Martin J, Putt M, Silber JH. Assessment of surfactant use in preterm infants as a marker of neonatal intensive care unit quality. BMC Health Serv Res 2011;11:22.

3. Valcamonico A, Accorsi P, Sanzeni C, Martelli P, La Boria P, Cavazza A, et al. Mid- and long-term outcome of extremely low birth weight (ELBW) infants: an analysis of prognostic factors. J Matern Fetal Neonatal Med 2007;20(6):465-471.

4. Tissieres P, Myers P, Beghetti M, Berner M, and Rimensberger PC. Surfactant use based on the oxygenation response to lung recruitment during HFOV in VLBW infants. Intensive Care Med 2010; 36(7):1164-1170.

5. Sweet DG, Carnielli V, Greisen G, Hallman M, Ozek E, Plavka R, et al. European consensus guidelines on the management of neonatal respiratory distress syndrome in preterm infants: 2010 update. Neonatology 2010;97(4):402-417.
6. Cools F, Askie LM, Offringa M, Asselin JM, Calvert SA, Courtney $\mathrm{SE}$, et al. Elective high-frequency oscillatory versus conventional ventilation in preterm infants: a systematic review and meta-analysis of individual patients' data. Lancet 2010;375(9731):2082-2091.

7. Verder H, Bohlin K, Kamper J, Lindwall R, Jonsson B. Nasal CPAP and surfactant for treatment of respiratory distress syndrome and prevention of bronchopulmonary dysplasia. Acta Paediatr 2009;98(9): 1400-1408.

8. Kessel I, Waisman D, Barnet-Grinnes O, Ben Ari TZ, Rotschild A. Benefits of high frequency oscillatory ventilation for premature infants. Isr Med Assoc J 2010;12(3):144-149.

9. Doyle LW, Faber B, Callanan C, Freezer N, Ford GW, Davis NM. Bronchopulmonary dysplasia in very low birth weight subjects and lung function in late adolescence. Pediatrics 2006;118(1):108-113.

10. Yoder BA, Siler-Khodr T, Winter VT, Coalson JJ. High-frequency oscillatory ventilation: effects on lung function, mechanics, and airway cytokines in the immature baboon model for neonatal chronic lung disease. Am J Respir Crit Care Med 2000;162(5):1867-1876.

11. Marlow N, Greenough A, Peacock JL, Marston L, Limb ES, Johnson $\mathrm{AH}$, et al. Randomised trial of high frequency oscillatory ventilation or conventional ventilation in babies of gestational age 28 weeks or less: respiratory and neurological outcomes at 2 years. Arch Dis Child Fetal Neonatal Ed 2006;91(5):F320-326.

12. Truffert P, Paris-Llado J, Escande B, Magny JF, Cambonie G, Saliba E, et al. Neuromotor outcome at 2 years of very preterm infants who were treated with high-frequency oscillatory ventilation or conventional ventilation for neonatal respiratory distress syndrome. Pediatrics 2007;119(4):e860-865.

13. Plavka R, Kopecky P, Sebron V, Svihovec P, Zlatohlavkova B, Janus V. A prospective randomized comparison of conventional mechanical ventilation and very early high frequency oscillatory ventilation in extremely premature newborns with respiratory distress syndrome. Intensive Care Med 1999;25(1):68-75.

14. Courtney SE, Durand DJ, Asselin JM, Hudak ML, Aschner JL, Shoemaker CT. High-frequency oscillatory ventilation versus conventional mechanical ventilation for very-low-birth-weight infants. N Engl J Med 2002;347(9):643-652.

15. De Jaegere A, van Veenendaal MB, Michiels A, van Kaam AH. Lung recruitment using oxygenation during open lung high-frequency ventilation in preterm infants. Am J Respir Crit Care Med 2006; 174(6):639-645.

16. Moriette G, Paris-Llado J, Walti H, Escande B, Magny JF, Cambonie $\mathrm{G}$, et al. Prospective randomized multicenter comparison of highfrequency oscillatory ventilation and conventional ventilation in preterm infants of less than 30 weeks with respiratory distress syndrome. Pediatrics 2001;107(2):363-372.

17. Baveja R, Christou H. Pharmacological strategies in the prevention and management of bronchopulmonary dysplasia. Semin Perinatol 2006;30(4):209-218

18. Ehrenkranz RA, Walsh MC, Vohr BR, Jobe AH, Wright LL, Fanaroff AA, et al. Validation of the National Institutes of Health consensus definition of bronchopulmonary dysplasia. Pediatrics 2005; 116(6):1353-1360.

19. Cools F, Henderson-Smart DJ, Offringa M, Askie LM. Elective high frequency oscillatory ventilation versus conventional ventilation for acute pulmonary dysfunction in preterm infants. Cochrane Database Syst Rev 2009(3):CD000104.

20. High-frequency oscillatory ventilation compared with conventional mechanical ventilation in the treatment of respiratory failure in preterm infants. The HIFI Study Group. N Engl J Med 1989;320(2): 88-93.

21. Johnson AH, Peacock JL, Greenough A, Marlow N, Limb ES, Marston L, et al. High-frequency oscillatory ventilation for the pre- 
vention of chronic lung disease of prematurity. N Engl J Med 2002; 347(9):633-642.

22. Krishnan RK, Meyers PA, Worwa C, Goertz R, Schauer G, Mammel MC. Standardized lung recruitment during high frequency and conventional ventilation: similar pathophysiologic and inflammatory responses in an animal model of respiratory distress syndrome. Intensive Care Med 2004;30(6):1195-1203.

23. Vento G, Matassa PG, Ameglio F, Capoluongo E, Zecca E, Tortorolo L, et al. HFOV in premature neonates: effects on pulmonary mechanics and epithelial lining fluid cytokines. A randomized controlled trial. Intensive Care Med 2005;31(3):463-470.

24. Sherlock RL, Anderson PJ, Doyle LW. Neurodevelopmental sequelae of intraventricular haemorrhage at 8 years of age in a regional cohort of ELBW/very preterm infants. Early Hum Dev 2005;81(11): 909-916.

25. Larroque B, Ancel PY, Marret S, Marchand L, Andre M, Arnaud C, et al. Neurodevelopmental disabilities and special care of 5-year-old children born before 33 weeks of gestation (the EPIPAGE study): a longitudinal cohort study. Lancet 2008;371(9615):813-820.

26. Volpe JJ. Brain injury in premature infants: a complex amalgam of destructive and developmental disturbances. Lancet Neurol 2009; 8(1):110-124.

27. Vidyasagar D, Velaphi S, Bhat VB. Surfactant replacement therapy in developing countries. Neonatology 2011;99(4):355-366.

28. Wang H, Gao X, Liu C, Yan C, Lin X, Yang C, et al. Morbidity and mortality of neonatal respiratory failure in china: surfactant treatment in very immature infants. Pediatrics 2012;129(3):e731-e740.

29. Halliday HL. Surfactants: past, present and future. J Perinatol 2008; 28(Suppl 1):S47-56.
30. van Kaam AH, De Jaegere AP, Borensztajn D, Rimensberger PC. Surfactant replacement therapy in preterm infants: a European survey. Neonatology 2011;100(1):71-77.

31. Ramanathan R, Sardesai S. Lung protective ventilatory strategies in very low birth weight infants. J Perinatol 2008;28(Suppl 1):S41-46.

32. Scopesi F, Calevo MG, Rolfe P, Arioni C, Traggiai C, Risso FM, et al. Volume targeted ventilation (volume guarantee) in the weaning phase of premature newborn infants. Pediatr Pulmonol 2007;42(10): 864-870.

33. Finer NN, Carlo WA, Walsh MC, Rich W, Gantz MG, Laptook AR, et al. Early CPAP versus surfactant in extremely preterm infants. N Engl J Med 2010;362(21):1970-1979.

34. De Jaegere AP, van der Lee JH, Cante C, van Kaam AH. Early prediction of nasal continuous positive airway pressure failure in preterm infants less than 30 weeks gestation. Acta Paediatr 2012; 101(4):374-379.

35. Mahmoud RA, Roehr CC, Schmalisch G. Current methods of noninvasive ventilatory support for neonates. Paediatr Respir Rev 2011; 12(3):196-205.

36. Han W, Song J, Liu A, Huo K, Xu F, Cui S, et al. Trends in live births in the past 20 years in Zhengzhou, China Acta Obstet Gynecol Scand 2011;90(4):332-337.

37. Zhu WX, Lu L, Hesketh T. China's excess males, sex selective abortion, and one child policy: analysis of data from 2005 national intercensus survey. BMJ 2009;338:b1211.

38. Binet ME, Bujold E, Lefebvre F, Tremblay Y, Piedboeuf B. Role of Gender in Morbidity and Mortality of Extremely Premature Neonates. Am Perinatol 2012;29(3):159-166.

This article is approved for Continuing Respiratory Care Education credit. For information and to obtain your CRCE

(free to AARC members) visit www.rcjournal.com

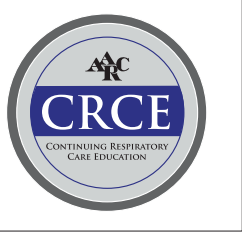

